\title{
Artikel
}

\section{Een aantal aspecten van de implementatie van de nieuwe richtlijn Consumentenkoop (Richtlijn 2019/771) nader belicht}

Mr. M. Bijloo*

\section{Inleiding}

Op 20 mei 2019 hebben het Europees Parlement en de Raad twee richtlijnen uitgevaardigd: Richtlijn 2019/770 betreffende bepaalde aspecten van overeenkomsten voor levering van digitale inhoud en digitale diensten, en Richtlijn 2019/771 betreffende bepaalde aspecten van overeenkomsten voor de verkoop van goederen. ${ }^{1}$ Over deze twee richtlijnen is al het nodige geschreven. ${ }^{2}$ Vanaf begin 2021 heeft het kabinet een aantal parlementaire documenten openbaar gemaakt die zien op de Nederlandse implementatie van deze twee richtlijnen. ${ }^{3}$ In het bijzonder het wetsvoorstel en de memorie van toelichting. ${ }^{4}$ Verschillende facetten van deze richtlijnen zijn nieuw in de zin dat zij bijna geheel nieuwe wetgeving introduceren. Dit geldt voor het merendeel van Richt-

Mr. M. Bijloo is advocaat en partner bij C-Legal te Amsterdam.

1. De volledige benaming is : Richtlijn (EU) $2019 / 770$ van het Europese Parlement en de Raad van 20 mei 2019 betreffende bepaalde aspecten van overeenkomsten voor levering van digitale inhoud en digitale diensten (hierna: Richtlijn digitale inhoud); Richtlijn (EU) 2019/771 van het Europees Parlement en de Raad van 20 mei 2019 betreffende bepaalde aspecten van overeenkomsten voor de verkoop van goederen.

2. Zie bijv. J.H.M. Spanjaard, Herziening consumentenrechten: verkenning van Richtlijn 2019/771, Contracteren 2019/3, p. 115-120; M.Y. Schaub, Nieuwe regels voor de consumentenkoop en overeenkomsten met betrekking tot digitale inhoud, NtEr 2019/9/10; M.B.M. Loos, Herziening regelingen kooprecht en digitale inhoud aanstaande, TvC 2019/3, p. 106-116; J.W. Rutgers, Kroniek van het Europees Privaatrecht, NJB 2020/960.

3. Kamerstukken II 2020/21, 35734, nrs. 1-7.

4. Kamerstukken II 2020/21, 35734, nr2. 2 en 3. lijn 2019/770, welke richtlijn voorschriften introduceert voor overeenkomsten tussen handelaren en consumenten voor de levering van digitale inhoud of digitale diensten. Andere items zien meer op een verduidelijking of uitbreiding van bestaande regels en concepten. Bijvoorbeeld de uitbreiding van het conformiteitsbegrip en de nadere regels voor garantiebewijzen in Richtlijn 2019/771 (hierna aangeduid als: de Richtlijn). In deze bijdrage wordt een aantal onderwerpen van (alleen) de Richtlijn besproken (Richtlijn 2019/770 wordt hier niet besproken). En dan niet zozeer de 'nieuwe' regels, maar juist een aantal bestaande regelingen in het Burgerlijk Wetboek (BW) die door de Richtlijn worden uitgebreid of vernieuwd: garanties, omkering bewijslast bij nonconformiteit, en remedies. Zonder uitputtend te willen zijn wordt met name stilgestaan bij een aantal opvallende en onduidelijke aspecten daarvan. ${ }^{5}$

5. Als algemene opmerking: de memorie van toelichting is her en der wat slordig. Waar dit betrekking heeft op de onderwerpen van deze bijdrage zijn deze slordigheden meegenomen. Waar dit niet het geval is, zijn deze slordigheden niet geadresseerd. Bijvoorbeeld de uitleg van de memorie van toelichting inzake art. 2 lid 1 van de Richtlijn. Hierin is de definitie van koopovereenkomst met betrekking tot consumenten opgenomen. Het gaat dan om 'elke overeenkomst waarbij de verkoper eigendom van goederen overdraagt of zich ertoe verbindt deze over te dragen aan een consument en de consument de prijs daarvan betaalt of zich ertoe verbindt die te betalen'. De memorie van toelichting - Kamerstukken II 2020/21, 35734, nr. 3, p. 26 - volstaat met de opmerking dat deze definitie al is opgenomen in art. 7:5 lid $1 \mathrm{BW}$. Dat is te kort door de bocht. Art. 7:5 lid 1 BW definieert de consumentenkoop als 'de koop met betrekking tot een roerende zaak die wordt gesloten door een verkoper die handelt in het kader van zijn handels-, bedrijfs-, ambachts- of beroepsactiviteit en een koper, natuurlijk persoon, die handelt voor doeleinden buiten zijn bedrijfs- of beroepsactiviteit'. Ingevolge art. 7:1 BW is een koop een overeenkomst waarbij de een zich verbindt een zaak te geven en de ander om daarvoor een prijs in geld te betalen. De consumentenkoop zoals gedefinieerd in de Richt- 


\section{Garanties}

Allereerst enkele algemene opmerkingen over de commerciële garantie onder de Richtlijn. De regeling is niet revolutionair gewijzigd ten opzichte van die in Richtlijn 1999/44. De meest in het oog springende wijziging is wellicht dat indien de producent de consument een garantie biedt, de producent onder de Richtlijn - kort gezegd - rechtstreeks aansprakelijk is tegenover de consument voor herstel of vervanging van de goederen in kwestie. Artikel 6 van Richtlijn 1999/44 inzake de garantie bevatte niet een dergelijke regel. Het bepaalde 'slechts' dat (1) de garantie moest vermelden dat de consument krachtens toepasselijke nationale wetgeving voor de verkoop van consumptiegoederen wettelijke rechten heeft (en dat de garantie deze onverlet laat), en (2) dat de garantie duidelijk de inhoud van de garantie vermeldt. Een ander verschil ziet op de situatie dat de garantie wordt genoemd in een reclame. Blijkt nu dat de voorwaarden in het commerciële garantiebewijs minder gunstig zijn voor de consument dan de voorwaarden in de reclame, dan gelden de voorwaarden zoals die genoemd worden in de reclame. Dit is anders als die reclame voor de sluiting van de overeenkomst werd gecorrigeerd op dezelfde of een vergelijkbare wijze waarop de reclame eerder was gemaakt. ${ }^{6}$

Daarnaast wordt in de algemene inleiding van de memorie van toelichting inzake de commerciële garantie nog opgemerkt dat - in het licht van het feit dat de term 'garantie' voor verschillende uitleg vatbaar is - garantiebewijzen worden gebruikt om de wettelijke rechten van de koper in te perken. De memorie van toelichting geeft als voorbeeld het geval waarin sprake is van een gebrek, en een koper uitsluitend het recht wordt gegeven om herstel te vorderen. Nu deze 'garantie' de koper het recht ontneemt op vervanging en ontbinding, is deze in feite aan te merken als een exoneratie (die bij een consumentenkoop vernietigbaar zou zijn ex artikel 7:6 lid 1 $\mathrm{BW}){ }^{7}$ De relevantie van deze opmerking is onduidelijk. De kern van de huidige garantieregeling is dat eventuele garantierechten of -vorderingen niets afdoen aan de wettelijke rechten en vorderingen van de koper (artikel 7:6a lid $1 \mathrm{BW}$ ) en dat de garantie dit ook moet vermelden (artikel 7:6a lid 2 BW). De sanctie op het nalaten daarvan is in beginsel vernietigbaarheid ex artikel 3:40 lid 2 BW (dan wel nietigheid). ${ }^{8}$ De nieuwe regeling wijzigt dit niet wezenlijk. Het genoemde praktijkvoorbeeld onderstreept de noodzaak van een wettelijke garantieregeling, maar maakt niet duidelijk hoe en in hoeverre de nieuwe regeling hierin verandering gaat brengen.

lijn wordt in het BW pas 'gecompleteerd' door art. 7:9 BW, welk artikel de verkoper verplicht om de verkochte zaak met toebehoren in eigendom over te dragen en af te leveren, dat wil zeggen in bezit te stellen van de koper.

6. Art. 17 lid 1 Richtlijn.

7. Kamerstukken II 2020/21, 35734, nr. 3, p. 29.

8. Zie ook Asser/Hijma 7-1 2019/127 e.v.; Asser/Sieburgh 6-III 2018/318 e.v.
Verder vallen de volgende aspecten van de garantieregeling in de Richtlijn op.

\subsection{Garantie producent}

De tweede zin van artikel 17 voorziet in een speciale regel voor het geval waarin een producent de consument een commerciële garantie van duurzaamheid biedt. ${ }^{9}$ De producent is dan - gedurende de volledige duur van de commerciële garantie van duurzaamheid - rechtstreeks aansprakelijk jegens de consument voor herstel of vervanging van de goederen (overeenkomstig artikel 14 van de Richtlijn). Zo wordt de producent wat betreft zijn verplichtingen tegenover de consument in een nagenoeg dezelfde positie geplaatst als de verkoper. De considerans van de Richtlijn bevat verder geen uitleg op dit punt. Dit wordt evenmin toegelicht in de memorie van toelichting. ${ }^{10}$ Echter, dit betekent blijkbaar wel dat verkopers die niet kwalificeren als producent - bijvoorbeeld elektronicaketens die rechtstreeks aan consumenten verkopen - niet aan deze regeling gebonden zijn. ${ }^{11} \mathrm{Zij}$ zouden derhalve garanties kunnen aanbieden met als enige recht of rechtsmiddel herstel, of een recht of rechtsmiddel qua tijd verkorten tot minder dan de volledige duur van de commerciële garantie. Deze verkopers blijven uiteraard wel aansprakelijk voor reparatie, vervanging, prijsvermindering en ontbinding onder de algemene conformiteitsregeling.

\subsection{Taal}

De garantie dient - net zoals overigens het geval was onder de garantieregeling in het kader van Richtlijn $1999 / 44^{12}$ - in duidelijke en begrijpelijke taal te zijn opgesteld. ${ }^{13}$ De Autoriteit Consument en Markt (ACM) heeft er in dit kader voor gepleit om in het wetsvoorstel op te nemen dat het garantiebewijs moet worden opgesteld in één of meer officiële talen van de Gemeenschap en in ieder geval in het Nederlands. ${ }^{14}$ Alhoewel het kabinet het belang van deze talen onderschrijft, stelt het kabinet dat deze taaleisen al geadresseerd worden door de eis dat een commercieel garantiebewijs in duidelijke en begrijpelijke taal opgesteld moet zijn. Volgens het kabinet brengt die eis met zich '(...) dat een verkoper die zich richt op de Nederlandse consument het garantiebewijs dient op te stellen in het Nederlands, of in het uiterste geval in een andere voor de Nederlandse consument begrijpelijke taal zoals het Engels' ${ }^{15}$ Dit is in die zin een 'novum' omdat de wetgever hier voor het eerst uitspreekt dat het vereiste van duidelijkheid en begrijpe-

9. Beoogde implementatie in art. 7:6a lid 2 BW, Kamerstukken II 2020/21, 35734, nr. 2.

10. Wel geeft de memorie van toelichting een uitleg van een duurzaamheidsgarantie. Zij verwijst hierbij echter naar een garantie van de verkoper, terwijl het hier nu juist draait om een garantie van de producent; Kamerstukken II 2020/21, 35734, nr. 3, p. 30.

11. Volledigheidshalve, art. 2 lid 4 definieert 'producent' als een fabrikant van goederen, een importeur van goederen naar de Unie, of elke andere persoon die zich als producent voordoet door zijn naam, handelsmerk of enig ander onderscheidend teken op de goederen aan te brengen.

12. Art. 6 lid 2 Richtlijn 1999/44.

13. Art. 17 lid 2 Richtlijn.

14. Bijlage bij Kamerstukken II 2020/21, 35734, nr. 3

15. Kamerstukken II 2020/21, 35734, nr. 3, p. 20. 
lijkheid voor garanties (van een verkoper die zich richt op Nederland) betekent dat de garantie ook in een andere taal dan het Nederlands kan worden opgesteld, voor zover die taal begrijpelijk is.

\subsection{Duurzame gegevensdrager}

Ingevolge artikel 17 lid 2 van de Richtlijn moet het commerciële garantiebewijs uiterlijk bij levering op een duurzame gegevensdrager aan de consument worden verstrekt. Artikel 2 lid 11 van de Richtlijn definieert een duurzame gegevensdrager als ieder hulpmiddel dat de consument of de verkoper in staat stelt om persoonlijk aan hem gerichte informatie op te slaan op een wijze die deze informatie toegankelijk maakt voor toekomstig gebruik gedurende een periode die past bij het doel waarvoor de informatie is bestemd, en die een ongewijzigde weergave van de opgeslagen informatie mogelijk maakt. De memorie van toelichting noemt als voorbeelden van duurzame gegevensdragers papier, USB-sticks, cd-rom's, dvd's, geheugenkaarten, harde schijven van computers, en e-mails. ${ }^{16}$ De memorie van toelichting verwijst hier bovendien naar het Content Servicesarrest. Hierin bepaalde het Hof van Justitie dat bij eventuele nieuwe duurzame gegevensdragers moet worden vastgesteld of die nieuwe dragers waarborgen dat de consument de verplichte informatie in bezit krijgt op dezelfde manier als in geval van een papieren drager. ${ }^{17}$ Dit om ervoor te zorgen dat een consument zijn rechten eventueel kan doen gelden. ${ }^{18}$ Overigens had ook rechtsoverweging 43 van dit arrest wellicht moeten worden genoemd. Hier verduidelijkt het Hof van Justitie dat sprake is van een duurzame drager indien de drager (1) de consument in staat stelt de bedoelde aan hem persoonlijk gerichte informatie op te slaan, (2) waarborgt dat de inhoud ervan niet wordt gewijzigd en dat de informatie gedurende een passende termijn toegankelijk is, en (3) de consument de mogelijkheid biedt om deze informatie ongewijzigd weer te geven.

De opsomming waarnaar het kabinet verwijst, is (inmiddels) enigszins ouderwets. In de praktijk zijn er bijvoorbeeld nog maar weinig gevallen waar garantiebewijzen op dvd's of cd-roms worden verstrekt. Het had hier op de weg van het Europees Parlement en de Raad gelegen - maar misschien zelfs ook op de weg van het kabinet om meer eigentijdse voorbeelden te noemen. Kan een producent of verkoper bijvoorbeeld een garantiebewijs via een $\mathrm{QR}$-code verstrekken?

16. Kamerstukken II 2020/21, 35734, nr. 3, p. 30. Overigens verwijst de memorie van toelichting hierbij naar de Richtlijn. Deze bevat echter niet een dergelijke lijst van voorbeelden. Waarschijnlijk werd in plaats daarvan Richtlijn 2011/83 bedoeld, waar in par. 23 van de considerans wel een dergelijke opsomming van voorbeelden is opgenomen.

17. Wel dient opgemerkt te worden dat dit arrest zag op duurzame gegevensdrager in de zin van Richtlijn 97/7. Het is dus de vraag of dit de interpretatie is van het kabinet of dat ook het Europees Parlement en de Raad dit op hun netvlies hadden bij het opstellen van de Richtlijn.

18. Kamerstukken II 2020/21, 35734, nr. 3, p. 30; HvJ EU 5 juli 2012, C-49/11, ECLI:EU:C:2012:419, NJ 2012/542 (Content Services), r.o. 42.

\section{Conformiteit en bewijslast}

Volgens de memorie van toelichting ligt de essentie van de Richtlijn in de conformiteitsregeling:

'De kern van de titels [titel 7.1 BW en 7.1AA BW] wordt gevormd door de conformiteitsbepalingen die bepalen wat de consument redelijkerwijze mag verwachten bij de anschaf van een product en welke middelen hem ten dienste staan indien het product niet aan deze redelijke verwachtingen beantwoordt. De conformiteit moet bestaan op het moment dat de consument het product geleverd krijgt. De verwachte levensduur van het product geldt hierbij als uitgangspunt. Deze conformiteitseis heeft een open karakter, in die zin dat de invulling ervan afhangt van de specifieke omstandigheden. Zo mag een consument een langere levensduur verwachten van een dure wasmachine, een auto of een smart TV dan van een goedkoop tosti-ijzer, computerkabeltje of app. ${ }^{19}$

In dit kader is de bewijslast met betrekking tot een eventuele non-conformiteit essentieel. Als gezegd, moet de conformiteit bestaan op het moment van levering. Dit betekent dat een koper moet antonen dat een eventueel gebrek ook bestond op het moment van levering. Om de consument tegemoet te komen geldt er onder het huidige artikel 7:18 lid $2 \mathrm{BW}$ gedurende de eerste zes maanden na aflevering een omkering van bewijslast. Met andere woorden, treedt een gebrek op binnen zes maanden na aflevering, dan wordt vermoed dat dit gebrek bestond ten tijde van de levering. Dit is alleen anders als de verkoper bewijst dat het gebrek op dat moment nog niet bestond (of als de aard van het goed of de non-conformiteit zich daartegen verzet). In dit verband is de consument niet gehouden om de oorzaak van de nonconformiteit te bewijzen, of te bewijzen dat de oorsprong hiervan te wijten is aan de verkoper. Bovendien moet de verkoper om an zijn bewijslast te voldoen, bewijzen dat de non-conformiteit voortvloeit uit een omstandigheid die zich na de aflevering van het goed heeft voorgedaan. ${ }^{20}$

Artikel 11 lid 1 van de Richtlijn verlengt deze termijn naar een jaar. Lid 2 biedt lidstaten zelfs de mogelijkheid de termijn van omkering van de bewijslast op twee jaar te zetten. Bij de implementatie hiervan geeft het kabinet als voorbeelden waarin de verkoper zou kunnen slagen in zijn bewijslast, de gevallen waarin de verkoper weet aan te tonen dat de non-conformiteit het resultaat is van een daad van de consument, of van een externe oorzaak die zich voordeed na levering aan de consument. Ook stelt het kabinet dat - conform paragraaf 45 van de considerans van de Richtlijn - ter weerlegging van een vordering van de consument inzake een conformiteitsgebrek de verkoper dient te bewijzen dat dit niet bestond

19. Kamerstukken II 2020/21, 35734, nr. 3, p. 6.

20. HvJ EU 4 juni 2015, C-497/13, ECLI:EU:C:2015:357, NJ 2016/148 (Faber), r.o. 70-75. 
op dat tijdstip. ${ }^{21}$ Overigens moet volledigheidshalve worden opgemerkt dat negatieve feiten in hun algemeenheid lastig te bewijzen zijn. Wellicht dat de verkoper hiermee uit de voeten kan op basis van deskundigenrapporten (bijvoorbeeld bij gebreken aan auto's of boten), maar over het algemeen zal dit buitengewoon lastig zijn.

Verder heeft onder andere de ACM er bij het kabinet op aangedrongen om gebruik te maken van de mogelijkheid om de termijn te verlengen naar twee jaar. ${ }^{22}$ Daar wil het kabinet echter niet aan. De reden daarvoor is allereerst duidelijkheid en zekerheid. Richtlijn 2019/770 voorziet ook in een termijn van een jaar wat betreft de omkering van de bewijslast. Maar deze richtlijn biedt niet de mogelijkheid tot verlenging naar twee jaar. Omwille van het belang van uniformiteit en de daaruit voortvloeiende zekerheid en duidelijkheid in de praktijk houdt het kabinet het bij een jaar voor de implementatie van beide richtlijnen. Daarnaast acht het kabinet het niet proportioneel om uit te breiden naar twee jaar, omdat de termijn van een jaar een (juiste) balans treft tussen de bescherming van de positie van de consument enerzijds en de verplichtingen voor verkopers anderzijds. $^{23}$

\section{Remedies}

\subsection{Algemeen}

Artikelen 13 tot en met 15 van de Richtlijn zien op de remedies van de consument in geval van non-conformiteit van de goederen. Deze artikelen zijn voor het grootste gedeelte al geadresseerd in de huidige artikelen 7:21 e.v. BW. Er is dan ook geen sprake van significante wijzigingen ten opzichte van de huidige regeling in het BW.

\section{- Duurzaamheid en 'refurbished' goederen/onderdelen}

De roep om duurzaamheid en het creëren van een circulaire economie klinkt de laatste tijd steeds luider. Neem bijvoorbeeld recentelijk de Europese Green Deal. ${ }^{24}$ Ook de Richtlijn onderschrijft het belang van duurzame goederen. Zo meldt de considerans van de Richtlijn: 'Zorgen voor duurzamere goederen is belangrijk om tot meer duurzame consumptiepatronen en een kringloopeconomie te komen.' Echter, duurzaamheid in dit verband ziet dan op:

'(...) de geschiktheid van de goederen om hun vereiste functies en prestaties bij normaal gebruik te behouden. Om conform te zijn, moeten goederen de duurzaamheid bezitten die voor goederen van hetzelfde

21. Kamerstukken II 2020/21, 35734, nr. 3, p. 34

22. Bijlage bij Kamerstukken II 2020/21, 35734, nr. 3.

23. Kamerstukken II 2020/21, 35734, nr. 3, p. 7-8 en 19-22; Kamerstukken II 2020/21, 35734, nr. 7, p. 6.

24. Zie voor meer informatie onder meer 'Delivering the European Green Deal', https://ec.europa.eu/info/publications/delivering-europeangreen-deal_nl. type normaal is en die de consument redelijkerwijs mag verwachten, gelet op de aard van de specifieke goederen, onder meer de mogelijke behoefte aan redelijk onderhoud van de goederen (...). ${ }^{25}$

De memorie van toelichting laat zich in gelijke bewoordingen uit over duurzaamheid: '[Duurzaamheid] betreft de geschiktheid van zaken om hun vereiste functies en prestaties bij normaal gebruik te behouden. Anders dan duurzaamheid voor het milieu gaat het hier dus om duurzaamheid in de zin van de levensduur van een product. ${ }^{26}$ De memorie van toelichting gaat iets verder dan de considerans van de Richtlijn: 'Zorgen voor duurzamere zaken is belangrijk om tot meer duurzame consumptiepatronen en een kringloopeconomie te komen (overweging 32 bij de richtlijn). Het repareren van een onderdeel van een zaak kan duurzamer zijn dan de hele zaak vervangen. Zo zal bijvoorbeeld een reiskoffer waarvan een wieltje het heeft begeven of is versleten met een nieuw wieltje weer prima te gebruiken zijn. Duurzaamheid in de zin van het streven naar levensduurverlenging van een product is echter geen doelstelling op zich van de richtlijn verkoop goederen. ${ }^{27}$

Met andere woorden, duurzame consumptiepatronen en de creatie van een kringloopeconomie zijn belangrijk. Daarbij kan - volgens de memorie van toelichting reparatie duurzamer zijn dan vervanging. Levensduurverlenging van producten is echter geen doel op zich van de Richtlijn. Dit betekent dan blijkbaar volgens de Nederlandse wetgever - voor zover dit überhaupt mogelijk is binnen de beperkingen van de maximum harmonisatie - dat duurzaamheid geen rol speelt bij de keuze voor een specifieke remedie.

In dit licht is het wellicht een gemiste kans van de Europese wetgever geweest om in het kader van reparatie en vervanging van een non-conform goed niet in te gaan op het eventuele gebruik van 'refurbished' of 'replacement' goederen. Beide begrippen hebben geen vastomlijnde betekenis, maar in het algemeen wordt hiermee gedoeld op goederen die geheel of voor een deel bestaan uit gebruikte onderdelen en na reparatie en testen weer op de markt worden gebracht. In sommige gevallen worden deze goederen ook weer opnieuw verpakt. Het kan ook gaan om goederen die zijn teruggestuurd naar de verkoper of producent die niet zijn gebruikt door een consument, maar die om wat voor reden ook niet op retailniveau verkocht zijn (bijvoorbeeld ingehaald door een nieuwe versie van het goed). Deze 'refurbished' of 'replacement' goederen worden doorgaans in ieder geval niet als 'nieuw' aangemerkt of als zodanig gepercipieerd. Het kan bijvoorbeeld gaan om een laptop die wegens een vermeend defect wordt geretourneerd aan de verkoper. De verkoper loopt deze laptop na, repareert eventuele defecten, test de laptop en biedt de laptop weer ter verkoop aan.

\footnotetext{
25. Par. 32 van de considerans van de Richtlijn

26. Kamerstukken II 2020/21, 35734, nr. 3, p. 27

27. Kamerstukken II 2020/21, 35734, nr. 3, p. 27
} 
In de Nederlandse jurisprudentie zijn in ieder geval twee voorbeelden te vinden met betrekking tot de inzet van 'refurbished' goederen. Beide hadden betrekking op Apple-producten. In het eerste geval ging het om een iPhone die na acht maanden onherstelbaar defect was. ${ }^{28}$ De consument wenste deze te vervangen door een nieuwe iPhone, terwijl Apple wilde volstaan met een 'refurbished' exemplaar. Dit laatste exemplaar was volgens Apple vergelijkbaar met de staat van de iPhone op het moment dat deze defect raakte. De kantonrechter besloot tot uitleg van artikel 7:21 lid 1 onder $\mathrm{c}$ in het licht van Richtlijn 1999/44 en het Quelle-arrest van het Hof van Justitie. ${ }^{29}$ In dit arrest oordeelde het Hof van Justitie kort gezegd dat indien de verkoper een non-conform goed levert, hij zijn verbintenis niet nakomt en derhalve aansprakelijk is voor de gevolgen daarvan. Indien de consument in dat geval een nieuw goed ontvangt ter vervanging van het non-conforme goed, is geen sprake van ongerechtvaardigde verrijking bij de consument. Volgens de kantonrechter kon dit niets anders betekenen dan dat de vervanging van een nieuw gekochte maar non-conforme zaak geëffectueerd moet worden door de koper een nieuw exemplaar te verschaffen (en niet een 'refurbished' exemplaar).

In de andere zaak ging het om een iPad die na vier maanden niet meer normaal was te gebruiken. ${ }^{30}$ De koper eiste een nieuw exemplaar als vervanging ex artikel 7:21 BW. Ook hier wilde Apple niet verder gaan dan een 'refurbished' of 'replacement' exemplaar. Dit omdat volgens Apple vervanging van de defecte iPad door een functioneel gelijkwaardige zaak voldeed aan het vereiste om een gebrekkige zaak in overeenstemming te brengen met de overeenkomst. Bovendien zou herstel ook niet leiden tot een 'nieuw' product. Ook hier oordeelde de kantonrechter dat het (hiervoor genoemde) Quellearrest tot geen andere conclusie kon leiden dan dat de consument die een nieuw maar non-conform product heeft gekocht, bij vervanging recht heeft op een nieuw product. Apple kon daarmee de defecte iPad niet vervangen door een 'replacement' exemplaar.

Echter, de prejudiciële vraag die werd voorgelegd aan het Hof van Justitie was of artikel 3 van Richtlijn $1999 / 44$ in de weg staat aan een nationale regeling die in geval van levering van een niet-conform consumptiegoed de verkoper het recht geeft om van de consument een vergoeding te eisen voor het gebruik van het nietconforme goed tot de vervanging daarvan door een nieuw goed. ${ }^{31}$ De Duitse regering had betoogd dat de consument ongerechtvaardigd verrijkt zou worden wanneer de consument ter vervanging van een non-conform goed een nieuw goed zou ontvangen zonder dat de consument gehouden zou zijn om een financiële vergoeding te betalen. Daarover overwoog het Hof van Justitie dat daar geen sprake van was, omdat de consument slechts

28. Rb. Amsterdam 8 juli 2016, ECLI:NL:RBAMS:2016:4197.

29. HvJ 17 april 2008, ECLI:EU:C:2008:231

30. Rb. Amsterdam 18 april 2017, ECLI:NL:RBAMS:2017:2519.

31. HvJ 17 april 2008, ECLI:EU:C:2008:231, r.o. 17. met vertraging een conform goed ontvangt, welk goed de consument van het begin af aan had moeten ontvangen. ${ }^{32}$

De vraag is echter of dit ook een-op-een kan worden gebruikt voor de beantwoording van de vraag of in geval van vervanging ook gebruikgemaakt mag worden van 'refurbished' goederen. Hetzelfde geldt voor eventuele 'refurbished' onderdelen in het geval van herstel. In dit verband, zoals hiervoor al opgemerkt, vormt volgens de memorie van toelichting de conformiteit van de goederen de essentie van de Richtlijn. De conformiteitsbepalingen zien niet alleen op wat de consument redelijkerwijze mag verwachten bij de aanschaf van een product, maar ook op de middelen van de consument indien het product niet aan deze redelijke verwachtingen voldoet. De conformiteit dient te bestaan op het moment van levering aan de consument, waarbij de verwachte levensduur van het product als uitgangspunt geldt. Daarnaast heeft de conformiteitseis een open karakter. De invulling hangt af van de specifieke omstandigheden. ${ }^{33}$

Als de verwachte levensduur van het product als uitgangspunt geldt, dan zou er ruimte moeten zij voor 'refurbished' onderdelen bij reparatie of 'refurbished' goederen bij vervanging op basis van artikel 7:21 BW. Dit is dan wel onderworpen aan de voorwaarde dat een goed dat is gerepareerd met 'refurbished' onderdelen of een goed dat is vervangen door een 'refurbished' goed diezelfde levensduur haalt. Bovendien dient de consument daar niet alleen bij aankoop uitdrukkelijk op gewezen te worden, maar ook bij een eventuele reparatie of vervanging. Het had op de weg gelegen van de Europese wetgever - en voor zover mogelijk binnen de beperkingen van de maximum harmonisatie ook op die van de Nederlandse wetgever - om dit onderwerp te adresseren in de Richtlijn, in het bijzonder gezien huidige klimaatdiscussies en -ontwikkelingen. ${ }^{34}$

\subsection{Kosteloos}

Artikel 14 lid 1 van de Richtlijn bepaalt dat herstel en vervanging kosteloos ${ }^{35}$ dienen te geschieden. Bovendien, ingeval een conformiteitsgebrek wordt verholpen door herstel of vervanging, moet op grond van lid 2 de consument de goederen ter beschikking stellen van de verkoper. De verkoper op zijn beurt neem de vervangen goederen op zijn kosten terug.

Hier is de Richtlijn wat onduidelijk. Artikel 1 lid 14 van de Richtlijn bepaalt dat onder 'kosteloos' moet worden verstaan 'vrij van de noodzakelijke kosten die zijn gemaakt om de goederen conform te maken, met name

32. HvJ 17 april 2008, ECLI:EU:C:2008:231, r.o. 40 en 41.

33. Kamerstukken II 2020/21, 35734, nr. 3, p. 6.

34. Zie voor een soortgelijk betoog naar aanleiding van Franse wetgeving op het gebied van reparatie en vervanging C.M.D.S. Pavillon, Duurzaam consumentenkooprecht: het Franse voorbeeld, WPNR 2020/7283, p. 367.

35. Codificatie van het Weber en Putz-arrest, HvJ EU 16 juni 2011, gevoegde zaken C-65/09 en C-87/09, ECLI:EU:C:2011:396, NJ 2011/462 (Weber/Wittmer en Putz/Medianess). 
de kosten van verzending, vervoer, werkuren of materiaal'. Als herstel of vervanging kosteloos dient te geschieden zoals hiervoor gedefinieerd, wat is dan het doel van de toevoeging dat de verkoper de vervangen goederen op zijn kosten terugneemt? En waarom alleen in geval van vervanging, en niet bij herstel? Dit lijkt een overbodige toevoeging dan wel 'verschrijving' te zijn, maar zou in theorie ook kunnen suggereren dat er ook gevallen zijn waarin herstel of vervanging niet 'kosteloos' is. Bovendien, wat wordt bedoeld met 'ter beschikking stellen van de verkoper'? Betekent dit dat de consument de verkoper meldt dat de non-conforme zaak kan worden opgehaald bij de consument? Of houdt dit een verplichting in voor de consument om het goed de verkoper toe te zenden? In beide gevallen brengt 'kosteloos' uit lid 1 dan wel met zich dat de verkoper de consument geen kosten in rekening mag brengen voor het vervoer c.q. de door de consument gemaakte verzendkosten aan de consument vergoedt. De Richtlijn blinkt hier niet uit in duidelijkheid.

Overigens bepaalt het huidige artikel 7:21 lid 2 dat de kosten van nakoming van de aflevering van het ontbrekende of herstel of vervanging niet aan de koper in rekening mogen worden gebracht. Volgens de memorie van toelichting is daar 'kosteloos' zoals gedefinieerd in artikel 2 lid 14 al geadresseerd en behoeft dit laatste artikel dus geen implementatie. ${ }^{36}$ Maar dit is dan mogelijk weer niet helemaal in lijn met de implementatie van artikel 14 lid 2 van de Richtlijn (de verkoper neemt vervangen goederen op zijn kosten terug). Als artikel 2 lid 14 van de Richtlijn geen implementatie behoefde, dan had ook artikel 14 lid 2 achterwege kunnen blijven. Maar dit heeft de Nederlandse wetgever wel overgenomen. Sterker nog, waar artikel 14 lid 2 van de Richtlijn rept over 'De verkoper neemt de vervangen goederen op zijn kosten terug', is dit in het Nederlandse wetsvoorstel - nieuw lid 7 van artikel 7:21 BW - uitgebreid tot vervanging en herstel: 'Bij een consumentenkoop stelt de koper de zaak ter beschikking van de verkoper voor herstel of vervanging. De verkoper neemt de zaak op zijn kosten terug. ${ }^{37}$ Op het eerste gezicht gaat dit dus verder dan de Richtlijn.

\subsection{Gebruiksvergoeding versus verbruiksvergoeding}

Ingevolge artikel 14 lid 4 van de Richtlijn hoeft een consument niet te betalen voor normaal gebruik van de vervangen goederen in de aan de vervanging voorafgaande periode. Dit wordt nader toegelicht in paragraaf 57 van de considerans van de Richtlijn: 'Als de verkoper het goed door middel van vervanging conform makt, mag de consument niet worden verplicht te betalen voor het normale gebruik van de goederen voordat zij werden vervangen. Het gebruik van de goederen moet worden beschouwd als normaal wanneer het in overeenstemming is met de aard en het doel van de goederen.' Zoals ook de memorie van toelichting meldt ${ }^{38}$ komt dit in wezen neer op een codificatie van het al eerdergenoemde Quelle-arrest. ${ }^{39}$

Dat is op zich duidelijke taal. Dat geldt niet voor de reactie van het kabinet op vragen van het CDA. Het CDA vroeg de regering naar de mogelijkheid van een verbruiksvergoeding in het geval dat een product na langere tijd vervangen wordt door een nieuwer model omdat het oorspronkelijke product niet langer voldeed aan de eisen. Het kabinet erkent de mogelijkheid van een ongerechtvaardigde verrijking van de consument indien een non-conforme zaak wordt vervangen voor een nieuwer model. Echter, het kabinet wijst in dat verband op het verbod op de gebruiksvergoeding in artikel 14 lid 4 van de Richtlijn. Maar het kabinet vervolgt dan:

'Het is echter wel denkbaar dat het redelijk is dat de consument in dit geval een vergoeding betaalt voor het nieuwere product. Bijvoorbeeld als een consument een wasmachine heeft gekocht die na zes jaar een gebrek vertoont dat niet gerepareerd kan worden en waarvan vastgesteld wordt dat het een gebrek aan overeenstemming betreft dat al bestond bij de aflevering. Vervolgens blijkt dat het model van deze wasmachine niet meer geleverd kan worden, waardoor vervanging alleen mogelijk is door een nieuwer model van een veel betere kwaliteit. Hierdoor kan de situatie ontstaan dat een consument ongerechtvaardigd wordt verrijkt. Het is uiteindelijk aan de rechter om per situatie te beoordelen of het vragen van een vergoeding op grond van de redelijkheid en billijkheid mogelijk is en of daadwerkelijk sprake is van ongerechtvaardigde verrijking.' 40

Met andere woorden, wordt een non-conform goed vervangen door een nieuwer model - en niet door een nieuw exemplaar -, dan ziet het kabinet wel mogelijkheden tot het betalen van een vergoeding door de consument voor het nieuwe(re) model. Dit zou dan zijn grondslag vinden in ongerechtvaardigde verrijking. Het gaat dus niet om betaling voor het gebruik van het oorspronkelijke maar non-conforme goed tot aan de vervanging, maar om vergoeding van de 'meerwaarde' van het nieuwere model in vergelijking met het oudere model.

De vraag is echter of dit met het oog op de maximum harmonisatie genoemd in artikel 4 van de Richtlijn wel mogelijk is. Daarnaast speelt hierbij ook de kwestie of een goed wel vervangbaar is. Het kan betoogd worden dat als een bepaald model koelkast uit productie is genomen en is opgevolgd door een verbeterd model, het oude model feitelijk niet meer vervangbaar is. ${ }^{41}$ In dat geval belandt de discussie in het vaarwater van artikel 13

\footnotetext{
8. Kamerstukken II 2020/21, 35734, nr. 3, p. 35.

HvJ 17 april 2008, ECLI:EU:C:2008:231

Kamerstukken II 2020/21, 35734, nr. 7, p. 9 en 10.

Zie ook Asser/Hijma 7-I 2019/553.
} 
lid 3 van de Richtlijn (vervanging onmogelijk) en dientengevolge van artikel 13 lid 4 van de Richtlijn (prijsvermindering of ontbinding).

\section{Conclusie}

De Richtlijn en de Nederlandse implementatie daarvan zorgen ten aanzien van de onderwerpen garantie, omkering bewijslast bij non-conformiteit en remedies voor de nodige verbeteringen c.q. verduidelijkingen. Hierbij springt de toelaatbaarheid van het gebruik van de Engelse taal in garantiebewijzen misschien het meest in het oog. Echter, zowel de Richtlijn als de Nederlandse implementatie zorgt ook weer voor onduidelijkheden. Bovendien hadden de Europese Commissie en de Raad in het kader van milieuduurzaamheid meer andacht kunnen besteden aan de beschikbare remedies bij nonconformiteit. 